\title{
SPECTROSCOPY IN AUSTRALIA
}

$\mathrm{T}$ HE fourth Australian Spectroscopy Conference, sponsored by tho Australian Academy of Scionce, and organized by a Committee under tho chairmanship of Prof. A. N. Hambly, was held in the Academy of Science Building and in the Australian National University, Canberra, during August 20-23. The Conforence was opened by Prof. N. S. Bayliss, chairman of the Academy's Standing Committee on Spectroscopy, who welcomed more than 300 participants and the fifteen firms exhibiting commercial spectroscopic equipment.

The programme was based on ten invited lectures and review papers, the first of which was by Dr. G. Herzborg (National Research Council, Ottawa) on electronic transitions of simple molecules. Following a summary of the ways in which the electronic states of simple polyatomic molecules are related to those of atoms and diatomic molecules, a description was given of the analysis of vibration-rotation bands, leading to a determination of the geometry of molecules in the ground and excited states. Difficulties in determining the change in symmetry on excitation and complications due to vibronic and JahnTeller interaction were described and illustrated by a discussion of the structures of $\mathrm{HNO}, \mathrm{H}_{2} \mathrm{O}, \mathrm{NCO}, \mathrm{HSiCl}$, $\mathrm{NH}_{3}, \mathrm{HNCN}$ and $\mathrm{CF}_{3} \mathrm{I}$.

The other invited speaker from overseas, Prof. M. Kasha (Florida State University), presented an account of a theory of electronic transitions in aggregates based on the exciton model and showed how this model can be translated into a consideration of the classical interactions of suitably aligned dipoles. The theory predicts shifts, splitting and selection rules which are substantiated by measured spectra of hydrogen-bonded dimers and by the absorption and luminescence spectra of dye aggregates. As a postscript, Kasha described the remarkable chemiluminescence observed when $\mathrm{ClO}^{-}$and $\mathrm{H}_{2} \mathrm{O}_{2}$ are mixed and which he interpreted as due to a transition in solvated oxygen.

A third review paper on molecular electronic spectra by Prof. N. S. Bayliss (University of Western Australia) was devoted to charge-transfer spectra of solutions with emphasis on the various interpretations of the BenesiHildebrand plot based on the formation of chargetransfer complexes or on cage phenomena. The quantum mechanics of the charge-transfer process were discussed in some detail, with particular roference to the manner in which the degreo of interaction is related to the ioniza. tion potential of the donor molecule and the electron affinity of the accoptor.

These invited lectures were followed by papers covoring many aspects of molecular electronic spoctra. G. Herzberg reported on recent work on free-radical spectra at the National Research Council of Canada, the radicals which have been studied including $\mathrm{NCO}, \mathrm{BO}_{2}, \mathrm{NCN}, \mathrm{HCO}$, $\mathrm{HNO}, \mathrm{HSiCl}, \mathrm{HNCN}, \mathrm{NH}_{2}, \mathrm{CH}_{3}$ and $\mathrm{CH}_{2}$, for which the geometrical structures in the ground and excited states have been determined. The flash photolysis of totracyanoethylene vapour was described by C. L. Cook, D. Kilpin and I. M. Napier (Chemistry and Physics Division, Weapons Research Establishment, Adelaide) and the spectra of $\mathrm{C}_{2}$ and $\mathrm{CN}$ roported. A. J. C. Nicholson (C.S.I.R.O. Division of Chemical Physics, Melbourne) described a windowless monochromator for studying photoionization efficiency curves in the $1600-850 \AA$ rogion and gave results for $\mathrm{Xe}, \mathrm{NO}, \mathrm{O}_{2}, \mathrm{CH}_{3} \mathrm{I}$ and $\mathrm{CH}_{4}$. The efficiencies of radiation-less transitions between excited electronic states were discussed by J. P. Byrne and I. G. Ross (Chemistry Department, University of Sydney) on the basis of tunnelling between the zero-point level of one state and vibrationally excited levels of lower states. With the observation that in extremely pure zone-refined anthracene both the energy transfer and luminescence cease to be markedly dependent on temperature, A. R. Lacey and L. E. Lyons (Chemistry Department, University of Sydney) suggestod that excitons and impuritylevels might act as traps for the excitation energy at sufficiently low temperatures, with the result that, in a mixed crystal of pure anthracene with any organic com. pound that fits reasonably well into the lattice, the fluorescence should come from both host and guest at higher temperatures. E. F. McCoy (Chemistry Department, University of Sydney) discussed the analysis of the absorption spectra of the vapour of azulene and azulene- $d_{8}$, while L. M. Logan (Chemistry Department, University of Sydney) presented data on the fluorescence spectra of these molocules both in the vapour phase and in solution. Analysis of the absorption and fluorescence spectra of anthracene in solid solution was reported by A. Bree and S. Katagiri (Department of Chemistry, University of British Columbia), while R. G. Body (Chemistry Department, University of Sydney) suggested that the electronic spectra of mixed crystals could bo calculated by perturbed matrix theory and illustrated the method by a model calculation on naphthalene crystals.

Theoretical considerations on the relation of the position and intensity of spectral transitions in the case of charge transfer complexes, where the transfer is more extensive in the ground state, were presented by R. D. Brown and E. K. Nunn (Department of Chemistry, Monash University) and illustrated by their results for some boron complexes. M. Batloy, A. Fulton, M. Lampard and L. E. Lyons (Chemistry Department, University of Sydney) showed that relativo electron affinitios of eloctron. accepting molocules and relative ionization-potentials of electron-donating molecules can bo obtained from charge transfer spectra. The effect of $p \mathrm{H}$, temperature and organic solutes on the spectra of three $\beta$-lactoglobins was discussed by H. A. McKenzie (Department of Physical Biochemistry, Australian National University, Canberra) in relation to tho current structural theories of these genetic polymorphs. Ultra-violet and infra-red spectroscopy were used by R. A. Jones (Department of Chemistry University of Adelaide) to show that the 2-pyrrolylmethylene iminos exist in the imine and not in the alternative amine form, while J. N. Phillips (C.S.I.R.O. Division of Plant Industry, Canberra) discussed the influence of various ligands on the spectra of zinc, nickel and iron porphyrin complexes.

The session on vibrational spectroscopy opened with an invited paper by $G$. Herzberg on the determination of the geometrical structure of simple polyatomic molecules by infra-red and Raman spectroscopy. Advances in instrumentation, particularly the advent of good infra. red detectors, thereby allowing full use of grating instruments, the discovery of the Raman effect and the development of microwave spectroscopy, have enabled accurate determination of the geometry of many small molecules. After discussing the vibrational and rotational energylevels of polyatomic molecules the theory was illustrated by the rotational Raman spectra of $\mathrm{CO}_{2}, \mathrm{CS}_{2}, \mathrm{C}_{2} \mathrm{H}_{2}$. benzone, allene and ethane and the vibrational-rotational spectra of acetylene, $\mathrm{HCN}, \mathrm{HCP}, \mathrm{CH}_{3} \mathrm{D}, \mathrm{CH}_{3} \mathrm{I}$, mothylacetylene and water. In conclusion, Herzberg discussed the variation of the $\mathrm{C}-\mathrm{C}$ and $\mathrm{C}-\mathrm{H}$ bond lengths in molrcules in terms of their molecular environment. 
In the following session, R. A. Ashloy and R. L. Werner (Dopartment of Chemistry, University of New South Wales) discussed tho analysis of tho high-resolution data for the $800 \mathrm{~cm}^{-1}$ fundamental of the pseudosymmotric top molecule HNCO, locating the bond centres at 777.12 cm-1 and determining tho $A, B, D$ and $H$ constants in both the uppor and lowor states. The infra-red spectra of both solid glyoxal and its vapour were shown by 1 '. J. Black, J. A. Burrows, A. R. H. Colo and D. J. Flias (Chomistry Departmont, University of Western Australia) to support the trans structure, while R. D. Brown, M. F. O'Dwyer and G. P. Poz (Department of Chemistry, Monash University) showed the vapour phase infra-red spectrum of $\mathrm{S}_{2} \mathrm{~F}_{2}$ to be consistent with the hydrogen peroxide FSSF structure. The low-resolution infra-red data for the vapour of $\mathrm{CN}_{\mathrm{g}} \mathrm{SeCN}$ wero shown by W.J. Franklin and R. L. Werner (Chemistry Department, University of Now South Wales) to bo consistent with a CSoC angle in excess of $130^{\circ}$, and with the aid of Raman and infra-red data for the liquid they wore able to make a complete vibrational assignment. V. Duokworth and R. L. Wornor (Chomistry Dopartmont, University of Now South Wales) presented infra-red and Raman data for solutions of cyanothioformamide together with the infra-red spectrum of the solid, and by comparison with deuterated and other derivatives were able to make a complete vibrational assignment. The infra-red and Raman spoctra of mono- and poly-halogenatod acotato ions wore discussed by E. Spinner (Department of Medical Chemistry, Australian National Univorsity) with particular attention to the offoct of polar and mass offects of the substituents on the symmetric and asymmetric carboxylato strotching frequencies and the preferred conformation of the ions. M. Colwell, B. James and P. E. Rogasch (Woapons Research Establishment, Salisbury) presented the infra-red spectra of some nitrophenols and discussed the effect and position of substitution on the asymmetric and symmetric nitro group frequencies. Emission and reflexion techniques for the study of the infra-red spectra of molten inorganic materißls at temperstures up to $1,000^{\circ} \mathrm{C}$ were discussed by J. K. Wilmshurst (C.S.I.R.O. Division of Chemical Physies. Melbourne) and results for the system $\mathrm{Zr}_{4} \mathrm{~F}-\mathrm{NaF}: \mathrm{KF}$ wore presented and interpreted in terms consistent with complex-ion formation. Differentiation between different barbiturates using infra-red spectroscopy was discussed by W. F. Ulrich, T. Johns and H. J. Sloano (Beckman Instruments, U.S.A.) and W. J. Cadman (Orange County Crime Laboratory, California, U.S.A.).

The study of association phenomenon by vibrational spectroscopy was the subject of six papers. A. D. Kidman and T. J. V. Findlay (School of Chomistry, University of Now South Wales) discussed the infra-red spectra in the $3 \mu$ region of mixtures of butanol and pyridine, and of chloroform and pyridine in carbon tetrachloride and derived thermodynamic properties of hydrogen bond formation. The use of partial deuteration as an aid to the study of inter- and intra-molecular hydrogen bonding of amidos and amines, and also as an aid to establishing the presence or absence of primary amino groups in unknown compounds, was illustrated by $\Lambda$. G. Moritz (Defence Standards Laboratory, Molbourne), whiln 'T. H. Renco (Chemistry Department, Wollongong University College) presented results of his investigations in tho $3 \mu$ region of the strong hydrogon-bonding between $p$-nitrophenol and alcohols in dilute carbon tetrachloride. HF. G. Higgins, A. J. Michell and B. J. Popploton (C.S.T.R.O. Division of Forrst Products, Molbourne) discussed the use of nuclear magnetic resonance spectroscopy in the determination of the conformation of pyranose sugars in solutions and also interproted tho infra-red data of the $\mathrm{OH}$ stretching region of these materials in terms of hydro. yen-bonding. Relative changes in the froqunneios and intensities of the stretching bands in HNCS and DNCS on hydrogen bond formation with acceptor molecules in carbon tetrachlorido solution were discussod by A. D. E. Pullin (Chemistry Department, Monash University) and related to polarization effects by the acceptor molecule. R. A. Cummins (Defonco Standards Laboratory, Molbourne) discussed his work on the effect of solvents on the frequency and intensity of the strotching band about $2100 \mathrm{~cm}^{-1}$ in thio- and isothio-cyanates and reported measurements on the frequency and intensity of the $\mathrm{CH}$ band of $\mathrm{CHCl}_{3}$ dissolved in theso materials. A study of low molecular woight organic and inorganic cations absorbed on highly oriented sheets of vermiculite by both X-ray diffraction and infra-rod spoctroscopy was prosented by R. H. Laby (Victorian. Dopartmont of Agriculture) with special emphasis on $\mathrm{N}-\mathrm{H}-\mathrm{O}$ hydrogen-bonding and the interaction of the $\pi$ olectrons of aromatic cations with the surface oxygen atoms. The sossion concluded with a paper by C. H. Burton, W. B. Lasich, J. H. Noon and R. W. Parsons (Physics Department, University of Queensland) on a study in the microwave region of the pressure broadening by $\mathrm{CO}_{2}$ and $\mathrm{N}_{2}$ of the absorption of $\mathrm{CH}_{3} \mathrm{Cl}$ due to inversion of the symmotric top molecule.

J. D. Morrison (C.S.I.R.O. Division of Chomical Physics, Melbourne) reviewed some aspects of modern mass spectromotric tochniques for tho identification and determination of molecular structure and discussed the possibility of programming a computer to compare the mass spoctrum of an unknown with a library of known spectra. Ha demonstrated a tape-rocording of a mass spectrum used for transfer of information from a mass spectromoter to a computer. Ho also described how the energy-levels of positive ions could be obtained from olnetron-impact moasurements and showed that a knowledge of probability laws could be used to distinguish different types of ioniza. tion procoss. J. S. Shannon (C.S.I.R.O. Division of Coal Research, Sydney) reported marked differences in the mass spectra of epimeric hydroxy- and acetoxy-cyclohexano dorivatives which ho found to be due to difforont modes of elimination of water or acotic acid from the different ions. The mass spectra of some alkenyl phenols wero presented by J. L. Occolowitz (Defence Standards Laboratory, Melbourne), who showed that the base peaks correspond to the rearranged ion type $R-\mathrm{CH}_{3}$, where $R$ represents the molecular ion less its alkenyl side-chein. thus permitting the number of phanolic hydroxyl groups to be determined. P. J. Morgan (Department of Pharmacology, Univorsity of Molbourno) reported infra-red and mass spectrometric data on some minor basic metabolites in human urine.

L. M. Jackman (Chemistry Departmont, Univorsity of Melbourne), in reviewing recent advances in nuclear magnotic resonances, commented that, whoreas there was one paper on nuclear magnetic resonance presented in 1961 at the third Conference, there were some 13 papers wholly or largoly devoted to this topic in Canberra. Recently, publications in this field have pourod out in excess of 300 per month.

Thren major oxporimental advanees which had greatly affected the application of nuclcar magnotic rosonanen techniques were higher magnetic fields, the locking of field and froqueney, and spin-decoupling. The advantages of the first were clearly illustrated in a subsequent paper by P. J. Black and M. L. Heffornan (Department of Chemistry, Monash University) in which indazole, an $A B C D E$ spectrum fairly strongly coupled at $60 \mathrm{Mc} / \mathrm{s}$ was sufficinntly 'first order' at $100 \mathrm{Mc} / \mathrm{s}$ to allow good starting values to be selected for the magnetic parameters.

Spin-spin dncoupling was introduced soon after the initial discoveries in nuclear magnetic resonanco, but had been popularized and refined recently largely due to the offorts of Fromman. Prof. Jackmon outlinod the relative merits of the field sweep mothod, where a constant frequency difference is maintained between the strong (or 'stirring') and the woak radiation whilo the spoctrum is scannod by a magnetic field, and the obverge case of fixed magnetic field and varying frequency difference. Not 
only can spectra be simplified by spin decoupling, but also chemical shifts between protons, or between protons and other species, can be measured with great accuracy by observing proton spectra, and relative signs of coupling constants can be determined. The use of a field sweep decoupler to assist in the assignment of a strongly coupled $A B C D E$ (benzofuran) was described later by $\mathbf{P}$. J. Black and M. L. Heffernan.

On the theoretical side, the practical details of calculation of spectra on digital computers and the use of iterative techniques to produce 'best-fitting' sets of magnetic parameters from observed spectra had beon largely pioneered and made practicable by Reilly and Swalen. Two papers presented discussed these points. S. N. Stuart and C. K. Coogan (C.S.I.R.O. Division of Chemical Physies, Melbourne) and P. J. Black and M. L. Heffernan reported the use of such programmes utilizing mothodsdiffering somewhat from one another and from that of Reilly and Swalen-which produced refined parameters from approximate starting values and discussed the probable errors in the parameters so derived.

The theoretical understanding of chemical shifts and spin-spin couplings had progressed with a number of new proposals recently. Long-range chemical shifts due to magnetic anisotropies and ring currents, of the type originally introduced by London, and recently extended and refined by Pople and by Jackman, Hall and Hardisson, were in fairly good agreement with theory. Recent results of Jackman, Porter and Underwood in Melbourne for $(3,2,2)$ cyclazene were reported.

The theory of spin-spin coupling was in a state of flux. The Karplus relation had been found to work well for nearly tetrahedral configurations, but the theory fails for hoterocycles or five-membered rings, and is being reexamined. A. D. Buckingham's suggestion of partial orientation of polar molecules in a strong electric field, backed up by theoretical treatment, had allowed absolute signs of coupling constants to be obtained and already it was established that a positive proton-proton coupling existed in nitrotoluene and a negative proton-fluorine coupling in fluoroform.

In addition to the papers mentioned here, L. K. Dyall (Newcastle University College, N.S.W.), S. Winstein and W. G. Young (University of California) discussed shieldings produced by steric interactions in a serios of quinone methides; D. J. Collins, J. J. Hobbs (Royal Hospital for Women, Paddington, N.S.W.), J. T. Pinhey (School of Chemistry, University of New South Wales), H. Rotten. dorf and S. Sternhell (C.S.I.R.O. Division of Coal Research, Chatswood, N.S.W.) reported the steric dependenco of long-range proton spin coupling in allylic systems; and A. J. Ryan (Department of Pharmacy, University of Sydney) reported results of infra-red and nuclear magnetic resonance investigations of phenylazopyrazolones.

In the less-represonted field of wide-line nuclear magnotic resonance, M. L. Heffernan, D. F. Kerr and P. D. Godfrey (Department of Chemistry, Monash University) illustrated the value of extra-proton nuclear magnetic resonance in an investigation of ${ }^{199} \mathrm{Hg}$ resonance in chloride comploxes, and G. J. Troup (Department of Physics, Monash University) outlined work on wide-line nuclear magnetic resonance in powdored radiation-damaged BeO. M. J. Bogaard (Chemistry Department, University of Sydney) presented results of $P Q R$ experiments on iodoand bromo-derivatives of five-membered hetorocycles, and the effects of other substituents. Of interest to experimentalists was the paper by G. V. H. Wilson (Department of Physics, Monash University) on the deconvolution of modulation-broadened spectra for a number of cases.

Several widely varied papers in electron-spin resonance were also delivered. H. F. Symmons (C.S.I.R.O. Division of Physics, Sydney) presented results of zero-field electronspin resonance in ferric acetylacetonate, with and without cobalt and aluminium dilution, from $4^{\circ} \mathrm{K}$ to $275^{\circ} \mathrm{K}$. J. R. Thyer and G. J. Troup (Department of Physics,
Monash University) reported the effect of annealing $\mathrm{BeO}$ crystals on the spin centres induced by radiationdamage. V. C. Bien, A. J. Harle, L. E. Lyons and J. C. Mackie (Chemistry Departmont, University of Sydney) had studied change transfer in solids in the presence of light by electron-spin resonance.

The session on stellar spoctroscopy began with a review by T. Dunham (Department of Astronomy, Australian National University) of our present knowledge of the spectra of stars and planets. He stressed the need for more sophisticated methods of direct photoelectric recording which would incorporate video systems for transmitting the spectral data to tapes for storage. The advances which would be possible when spectra could be observed from satellites were outlined. During tho Conferenco, many members visited. Mount Stromlo Observatory where they inspected the 74-in. telescope and associatod Coudé spectrograph designed by Dunham.

H. Gollnow (Mount Stromlo Observatory, Canberra) roviewed our present knowledge of 'magnetic stars' and pointed out that there were many puzzling foatures in the observed Zeeman effects which could not be explained by any one model. High-dispersion spectral studies of R. Y. Sagittarii were reported by I. J. Danziger (Mount Stromlo Observatory, Canberra), who concluded that the main mass of the stars must bo spectroscopically invisible helium and the source of continuous opacity is photoionization of neutral carbon rather than the negative carbon ion. The luminosity classification of $G$-type stars was discussed by W. Buscombe and C. Dickens (Mount Stromlo Observatory, Canberra), who pointed out that it was possible from spectra of moderately high dispersion to distinguish effects of pressure in stellar atmospheres. B. E. J. Pagel (at Mount Stromlo Observatory, on leave from Royal Greenwich Observatory) discussed the abundances of metals in cool dwarfs and sub-giants, the data indicating that apparently all the main nucleosynthesis processes were essentially completed in the disk of the Galaxy by the time the oldest galactic clusters were formed. Studies of sub-giants show a range in metal abundance correlated with motion perpendicular to the galactic plane, but not with age. A. Przybylski (Mount Stromlo Observatory, Canberra) reported a very peculiar composition of the star $H D 101065$, which has an effective temperature $400^{\circ} \mathrm{C}$ higher than the Sun. The spectrum shows the presence in its atmosphere of only the rare earths besides hydrogen and traces of cadmium. Many fairly strong absorption lines are due to holmium, which has not yot been identified with cortainty in the Sun or in stars.

The session on analytical applications of X-ray fluorescence spectroscopy began with a review by W. M. B. Roberts (Bureau of Mineral Resources, Canberra) of the devolopments leading to modern techniques. T. R, Sweatman and K. Norrish (C.S.I.R.O. Division of Soils. Adelaide) then discussed the determination or correction for the mass absorption coefficients and illustrated the application of these methods in the analysis of a wide range of natural materials. Methods for increasing sensitivity were described by K. P. Champion and R. N. Whittem (Australian Atomic Energy Commission Research Establishmont, Lucas Heights, N.S.W.), while R. N. Whittem reported on the determination of strontium in samples of biological and geological interest. The analysis of mator. ials adsorbed on alumina was described by V. J. Manners and F. H. Scott (Defence Standards Laboratory, Alexandria, N.S.W.), and I. Macdonald (Philips Electrical Industries, Sydney) discussed the general problem of $X$-ray spoctrographic analysis without standards, using a method of successive approximations.

The review of atomic emission spectroscopy by S. R. Taylor (Department of Geophysics, Australian National University) stressed the desirability of increasing sensitivity to the 'part-per-billion' level and discussed various approaches to the problem. The applications of direct- 
roading spectrographs and tape machines to control of a non-ferrous smelting process and to the analysis of stool work raw materials were doseribed by M. D. Amos and P. C. Thomas (Sulphide Corporation Pty., Ltd., Newcastle, N.s.W.) and by Z. Collison and 'T. Seott (Tho Broken Hill Propriotary Company, Ltd., Newcastle, N.S.W.). The use of the briquetting technique and direct readers was described by T. Scott and B. Shanley (The Broken Hill Propriotary Company, Ltd., Nowcastlo, N.S.W.) with reference to the analysis of steelworks raw materials and by K. R. Walker (Burouu of Minersal Resources, Can borra) with reforenee to tho analysis of rocks and soils. D. J. Swaine (C.S.I.R.O. Division of Coal Resoarch, Chatswood, N.S.W.) gave details of the semi-quantitativo mothods he has doveloped for tho analysis of matorials oncountered in coal research. Tho carrier distillation method for the analysis of refractory materials was used by L. S. Dalo (Australian Atomic Energy Establishmont, Lucas Heights, N.S.W.), who discussed the function of the 'carrier' in the matrix. 'The operational requirements of a small plasma jot of stablo intensity wero discussed by R. H. Brockman and R. N. Whittom (Australian Atomic Energy Establishment, Lucas Heights, N.S.W.). The final papors in tho session by $\mathbf{F}$. Broeh and $J$. Schuch (Jarrell-Ash Company, U.S.A.) described the use of a laser for vaporizing small areas of sample, tho resulting vapour boing oxcitod by a spork dischargo. The technique offers attractive possibilities as a microprobe.

D. J. David (C.S.I.R.O. Division of Plant Industry, Canberra) gave a comprehensive review of recent dovelop. ments in atomic tbsorption spectroscopy which revealed a rapidly widening accoptanco of the mothod, and he suggested that recent improvements in light sourcos and atomizors would load to sensitivities in the 'parts-perthousand-million" rango for most of the 30 oloments which are now regularly determined by atomic absorption mothods. A further 20 olomonts are now detectable at 'part-por-million' levels in incandoscont oxy-acotylene flames. J. E. Allan (Rukuhia Soil Research Station, Now Zoaland) roported results for elements having their strongest resonance lines below $2000 \AA$. For solenium the $1960 \AA$ line gives a detection limit of 0.5 p.p.m. with a hydrogen flamo. For arsenic a detection limit of I p.p.m. was obtained with tho 1890 \& lino, but the lines at 1937 and $1972 \AA$ are preferable. Experiments with tho morcury lino at $1849 \AA$ havo so far boon unsucesssful. J. V. Sullivan and A. Walsh (C.S.I.R.O. Division of Chemical Physics, Melbourne) described new atomic spectral lamps which gavo a hundrod-fold incresse in resonance line intensity compared with conventional hollow-cathodes, and also yielded more linear calibration curves. The high intonsity makes possible detection by resonance absorption and re-emission. M. D. Amos and P. E. Thomas (Sulphide Corporation Pty, Litd., Nowcastlo, N.S.W.) described a spray ohumber and burner giving improved stability and sensitivity and reported a detection limit of 0.8 p.p.m. aluminium using an oxy-acotylons flame.

C. S. Rann and A. N. Hambly (Dopartmont of Chemistry, Australian National University) reported the distribution of tho atoms of somo common metallic elements in the type of flarne commonly used in atomic absorption spoctroseopy and in a second papor roportod proliminary results on the determination of solenium. $K$. Collier and H. C. T. Stace (C.S.I.R.O. Divisions of Mathematical Statistics and Soils, Adelaido) described a statistioal mothod for dotormining the optimum condition for maximum absorption, whilo G. C. Baird and B. Envali (Defoneo Standards Laboratory, Melbourno) roportod various anion effects. The application of atomic absorption spectroscopy to the detormination of metals in alloys, paints and plistors was described by G. C. MoPhorson (John Lysaght (Aust.) I.td., Newcastle, N.S.W.) and methods for the determination of chromium, manganese and nickel in iron and steel wore reportod by $\mathrm{K}$. Kinoon and C. B. Bolcher (Tho Broken Hill Proprietary Company, Shortland, N.S.W.). G. R. Hercus (C.S.I.R.O. Division of Chemical Physics, Melbourne) discussod the possibilitios and limitations of G. $R$. Tsaak's method for the dotermination of the profiles of atomic resonance lines and $J . J$. MoNoill (C.S.I.R.O. Division of Chomical Physics, Melbourne) roported on the performance of a monochromator he had designed for manufacture in Australia, utilizing plane gratings ruled on the C.S.I.R.O. ruling ongino. A notable featuro was the particularly small amount of scattered light. Elegant mothods for automatically maintaining parallelism in interforomotor platos, or for scanning over soveral orders, wore described by J. V. Ramsey (C.S.I.R.O. Division of Physics, Sydney). This instrument also is expected to be manufacturod in Australia.

The 15 exhibitors presented a wide range of spectroscopic equipment. Of particular interest was tho exhibition for the first time at theso conferences of Australian-made oquipment, including an atomic absorption spectrophotomoter, atomic spestral lamps, a grating monochromator and microwavo-poworod Raman lamp.

At the end of this vory successful conference it was announced that the fifth Australian Spectroscopy Conference will be held in Porth in 1965.
C. IK. COOGAN
J. D. MorRison
A. WALSH
J. K. WIIMshurst

\section{COLLAGEN RESEARCH IN CZECHOSLOVAKIA}

\begin{abstract}
IN many ways the first International Crochoslovakian I Symposium on Collagen, held at Velké Karlovico during Septembor $2-7$, was tho most interesting meeting of its kind sinco the Cambridgo symposium of 1957 . At that timo thero was virtually no fundamental rosearch boing carried ont at C.S.S.R. institutes into connective tissuo, with the exception of $M$. Chvapil, who might bo regarded as the doyen in this field. It was the clear intention of tho organizers, comprising the food institute, the three Ifathor institutes, tho rheumatism instituto and the instituto of hygione and occupational diseases, to acquaint thoir guests with tho offort now boing directed at collagon, and there can be no doubt that tho oyos of Western obsorvers have been opened widely both to the oxtont of dotailed work now boing carried out in the C.S.S.R. and to the enthusiasm with which it is dono.
\end{abstract}

Although it cannot be said that all of this contribution is original in concopt, a very clear understanding of tho collagen field was amply demonstrated in four excellent roviow studios: "The Biosynthesis of Collagen", by J. Hurych; "Exporimental Lathyrism", by J. Rosmus; "Analysis of High Molocular Brokkdown Products of Collagn", by 7. Deyl; "The Tochnical Aspocts of Roconstituted Collagons", by C. Halómek.

It was a strong point of this morting that it was not dominated by uny single disciplino, although contributions from Sam Soiftor (Now York), H. Noda (Tokyo) and $\Lambda$. Nordwig (Munich) ensured that amino-acid sequence oxporimonts in sollagen and tochniques utilizing collagenases wero woll ropresonted. Both roconstituted collagon and the effects of ionizing radiation were major points for disenssion and these woro often linkod together; 